\title{
SYSTEMIC RISK OF THE GLOBAL BANKING SYSTEM - AN AGENT-BASED NETWORK MODEL APPROACH
}

\author{
Tomáš Klinger, Petr Teplý*
}

\begin{abstract}
:
The global banking system proved significantly vulnerable to systemic risk during the 2007-2009 financial crisis. In this paper, we construct an agent-based network model of systemic risk to a banking system, and use it for stress-testing of several different regulatory measures. First, our simulations confirm that sufficient capital buffers in individual banks are crucial for protecting the stability of the whole system. Second, we show that the regulatory measures installed as preventive measures to ensure that the banks possess sufficient capital buffers have almost no positive effects on stability when the system is collapsing. Finally, we highlight various data deficiencies which prevent the researchers and regulators from fully understanding the complete range of systemic risk and make it difficult to devise effective and targeted regulatory measures at this time.
\end{abstract}

Keywords: agent-based modelling, banking regulation, Basel III, capital, interbank network, systemic risk

JEL Classification: E61, G01, G21, G28

\section{Introduction}

The 2007-2009 global financial crisis highlighted the vulnerabilities and interdependencies in the financial system, bringing about a revision of financial regulations. The crisis also exposed the deficiencies of Basel II, showing that the regulatory measures had fallen victim to regulatory capture by large international banks, failing to ensure sufficient capital buffers (Lall, 2010, p. 15). The subsequent regulatory framework revisions finally coalesced into the publication of Basel III that was intended to increase the banking system's resilience by redefining what constitutes the regulatory capital, raising the current capital ratios and adding new ones (BCBS, 2011). It also adds measures for increasing the banks' liquidity so that they are better able to withstand transient shocks. Although we can expect the new measures to bring minor improvements, there are several reasons why ideal regulation is still absent and not yet achievable (Teplý, 2012, p. 4). First, it is necessary to eliminate the political and institutional pressures that influence global financial operations. Second, the parameters of the regulatory measures should be an outcome of rigorous research rather than

* T. Klinger, Institute of Economic Studies, Faculty of Social Sciences, Charles University in Prague, Opletalova 26, 11000 Prague 1 (tomas.klinger@seznam.cz); P. Teplý, Faculty of Finance and Accounting, University of Economics, Prague, nám. W. Churchilla 4, 13067 Prague 3 (petr.teply@vse.cz). This research was supported by the Czech Science Foundation (project GACR No. 14-02108S - The nexus between sovereign and bank crises), project VŠE IP100040 and by a grant from the CERGE-EI Foundation under a program of the Global Development Network. All opinions expressed are those of the authors and have not been endorsed by CERGE-EI or the GDN. 
lobbying by large financial institutions and the systemic character of the banking system should be taken into account.

In this paper, we contribute to the discussion for better regulation by shedding light on systemic risk and by showing a way how regulatory measures can be tested in a virtual environment. Our method stems from the research on systemic risk using the network approach, which became a trendy topic after the recent financial crisis. An overview of the network character of the crisis can be found in Sheng (2010), in the risk assessment framework for systemic linkages provided in IMF (2009) and in the recent advances in modelling systemic risk using network analysis provided by ECB (2010). More recently, Frait and Komárková (2011) or Geršl and Jakubík (2010; 2012) present systemic risk in the context of financial stability and macroprudential policy from a view of the Czech National Bank. On a related note, a detailed literature survey of research focused on the interconnected financial structures is provided by Allen and Babus (2009).

Current research can be divided into two categories, the empirical studies and theoretical models. The empirical studies are focused on modelling of the real-world interbank exposures and the banking systems' disposition to crisis caused by contagion effects. These models usually describe local banking systems as documented by Boss, et al. (2004) for the Austrian interbank market or Upper and Worms (2004), Wells (2004), Van Lelyveld and Liedorp (2006) or Muller (2006) for other countries. However, a frequent problem of the empirical approach is that the data on the individual interbank exposures is unavailable to the researchers who often rely only on the aggregate balance sheet data. For this reason, the majority of empirical studies use the maximum entropy assumption, which supposes that the banks spread their lending as evenly as possible given a certain sum of their interbank assets (Upper, 2011, p. 6). Clearly, this assumption is rather unrealistic and it often underestimates the potential for contagion (Mistrulli, 2011) or underreported inventory of bad loans carried on the books.

The theoretical models examine how system behaviour is influenced by its general characteristics. The first such model was constructed by Allen and Gale (2000) who showed that the structures with more interbank links are more resilient to initial shocks. Another early analysis is provided by Freixas, et al. (2000), who studied contagion in systems where some banks are systemically important. The simple framework is extended in Cifuentes, et al. (2005) and Shin (2008), who add a mechanism for price decrease of illiquid assets as a second channel of contagion. Finally, there are models using simulations on random networks such as Battiston, et al. (2012) or Gai and Kapadia (2010), who find out that the interbank exposures serve as a good shock absorber initially but when a crisis occurs, they can cause a larger negative impact. Our paper is inspired by Nier, et al. (2007), who built an agent-based model of interbank systems and finds non-linear dependencies on certain parameters when performing comparative statics exercises.

The paper is structured as follows: In the second section, we build a model of a banking system that allows us to perform scenario stress analysis under various settings of 
structural properties and regulatory environments. The third section presents detailed results of our simulations. In the fourth section, we provide a results summary and discuss further opportunities for our research. Finally, the last section concludes the paper and states the final remarks.

\section{The Model}

In this part, we provide a high-level overview and detailed description of the model construction. Furthermore, we explain an impact of shocks to bank balance sheets and discuss effects of systemic risk on bank capital regulation.

\subsection{Basic description}

We create a system that comprises a number of banks interconnected by exposures and claims they hold against each other. Our interbank system is characterized by a graph where the banks are represented by nodes and their exposures by oriented edges. Such system may represent an interbank market, a network of over-the-counter (OTC) derivatives or payment systems. In order to be able to study the relationship of the system behaviour and its characteristics, and because the data on interbank exposures are mostly unavailable, we perform our simulations on a generic random network as described by Erdös and Rényi (1959). Hence we assume identical and independent probability of interbank exposures across all ordered pairs of banks. However, if in the future the data were available, the model is applicable to any interbank network.

The interbank network is examined under a simulated stress scenario, when one or several banks receive a negative shock to the asset side of their balance sheet. The shock is then transmitted to the rest of the banks through one of the two main mechanisms described in Brunnermeier et al. (2009, p. 15): the "domino" effect meaning the transfer of losses through the edges of the network. ${ }^{1}$ As the model represents only a very short period of collapse, we assume that the banks are not capable of borrowing any extra funds and that no edge can be added to the interbank network, and that the banks do not make any profits during the simulation. In our study, we also restrict the possibility of state aid in the form of bank bail-outs. Our analysis is based on comparative statics experiments where the simulations are performed under varying combinations of input parameters. These parameters are summarized in Table 1 along with their base values used in Nier et al. (2007) which we use for our simulations unless stated otherwise.

In contrast to Nier et al. (2007), our model is also able to capture rules that represent several types of banking regulation contained in Basel III. ${ }^{2}$ Namely, in this paper we

1 The second contagion channel called the "asset price spiral" effect, which represents the asset price decline under low liquidity of the system, will be left for further research.

2 For more details on Basel III and its predecessor Basel II see, for instance, Klinger (2011), Lall (2010), Matejašák et al. (2009), Rippel and Teplý (2011), Teplý et al. (2007; 2012) or Šútorová and Teplý (2013). 
apply a situation where the regulator deprives a bank of its license because of a low capital ratio. To our knowledge, we are the first to study the effects of regulation in an agent-based interbank network model.

Table 1:

Input Parameters of the Model

\begin{tabular}{|l|l|r|}
\hline Parameter & Interpretation & \\
\hline $\boldsymbol{N}$ & Number of banks in the system* & 25 \\
\hline $\boldsymbol{P}$ & Probability of connecting two banks with a directed exposure* $^{*}$ & 0.2 \\
\hline $\boldsymbol{E}$ & Total sum of external assets in the system & 100,000 \\
\hline $\boldsymbol{V}$ & Interbank asset ratio (interbank/total assets) $^{*}$ & 0.2 \\
\hline $\boldsymbol{C A D 1}$ & Capital ratio (net worth/internal + external assets) & 0.05 \\
\hline shock $_{\text {random }}$ & Capital ratio limit that triggers bank's removal by the regulator & 0 \\
\hline shock $_{\text {others }}$ & Shock on a random bank (in percentage of external assets) & 1 \\
\hline iterations & Shock on all other banks (in percentage of external assets) & 0.1 \\
\hline
\end{tabular}

Note: Parameters highlighted by asterisks are used by Nier, et al. (2007) and for the sake of comparability, we set them to the same values in the basic setting. The rest of the parameters are original to our model.

Source: Authors

\subsection{Model construction}

On the level of an individual simulation, the model is built as follows: first, the interbank network is initialized along with the individual banks' balance sheets. Second, we shock the system by wiping out a portion of certain banks' assets and several rounds of defaults and loss transmission unfold. The model runs in several laps (rounds of defaults) until the shock dissipates in the banking system and is not propagated further.

\subsubsection{Interbank network creation}

The interbank network is based on two main parameters, which are set at the beginning of a simulation run and which define the form of the random graph:

1. Node count $N$, which determines the number of banks in the network,

2. Probability $p_{i j}$, with which there is an oriented edge between node $i$ and node $j$ in the graph, i.e. the probability that the bank $i$ is exposed to the bank $j$. We expect this number to be fixed among all edges between nodes $(i, j)$ and denote it as $p$. There can be two links between a pair of edges, each in different direction.

Subsequently, the network is created in two steps: First, there are $N$ banks added to the system, and second, for each oriented pair of banks, an edge is created with probability $p$. 


\subsubsection{Initialization of balance sheets}

Next, we initialize the individual banks' balance sheets for the given network realization. This is done in such manner that the variables conform to the aggregate level identities as well as the bank level identities. First, we calculate the global variables of the system. On the aggregate level, the total value of assets is a sum of interbank assets (constituted by all the loans represented by the edges of the interbank network) and external assets (constituted by individual banks' exposures outside the network, e.g. securities and loans to other entities such as households, sovereigns or non-financial institutions).

1. The sum of external assets in the system (denoted by $E$ ) and the ratio of interbank assets to total assets (denoted by $\theta$ ) are given as input parameters. The total value of assets in the system (denoted by $A$ ) is calculated as

$$
A=\frac{E}{(1-\theta)} .
$$

2. The total sum of interbank assets is then determined as a portion of total assets.

$$
I=\theta A
$$

3. If we denote the sum of outgoing edges from all the banks in the system as $Z$, the value of one individual edge is calculated as

$$
w=\frac{1}{Z} \text {. }
$$

Subsequently, individual banks' balance sheets are initialized:

4. An individual bank's interbank assets $\left(i_{i}\right.$ and liabilities $\left(b_{i}\right)$ are calculated according to the interbank network structure:

$$
\begin{aligned}
& i_{i}=\text { w.number of incoming edges } \\
& b_{i}=\text { w.number of outgoing edges }
\end{aligned}
$$

5. The value of an individual bank's external assets is a little more difficult to determine. We use the same two-step algorithm as Nier, et al. (2007):

a. First, each bank's difference between the internal liabilities and internal assets is balanced by a certain amount of external assets $\tilde{e}_{i}$.

$$
\begin{array}{ll}
\tilde{e}_{i}=b_{i}-i_{i} & \text { if } b_{i}-i_{i}>0, \\
\tilde{e}_{i}=0 & \text { if } b_{i}-i_{i} \leq 0 .
\end{array}
$$

b. The rest of the total sum of external assets is then distributed uniformly among the banks. Finally, it holds that

$$
e_{i}=\tilde{e}_{i}+\left[\frac{E-\sum_{i=1}^{N} \tilde{e}_{i}}{N}\right]
$$

6. Each bank's net worth is calculated as a portion of total assets according to the following capital ratio:

$$
n_{-} w_{i}-\gamma a_{i}
$$


7. External liabilities are calculated so that the balance sheet identity holds:

$$
d_{i}=a_{i}-n_{-} w_{i}-b_{i}
$$

Finally, as the balance sheets are populated, the whole system is initialized and ready for the simulation.

Table 2

Balance Sheet of an Individual Bank in the Model

\begin{tabular}{|l|l|}
\hline $\boldsymbol{a}_{i} \ldots$ TOTAL ASSETS & $\boldsymbol{I}_{\boldsymbol{i}} \ldots$ TOTAL LIABILITIES \\
\hline$i_{i} \ldots$ interbank assets & $b_{i} \ldots$ interbank liabilities \\
\hline \multirow{2}{*}{$e_{i} \ldots$ external assets } & $d_{i} \ldots$ external liabilities (deposits) \\
\cline { 2 - 2 } & $n_{-} w_{i} \ldots$ net worth \\
\hline
\end{tabular}

Source: Authors

\subsubsection{Shock}

After the initialization, the system is in inertia until we induce an adverse shock, which initiates the first lap of the simulation. There are two types of shocks we can examine:

- A certain portion (most often $100 \%$ ) of external assets is wiped out from the balance sheet of a random bank - we call this a "local shock".

- The external assets drop in value. This means that the percentage loss is applied to all banks - we call this a "global shock".

\subsubsection{Shock impact on a bank's balance sheet}

The initial shock may result in knock-on "domino" effects, where in each lap of the simulation, the set of banks that suffered losses transmit the shock further in a cascade effect. Let us consider one representative bank that receives a shock. Whatever the shock type, it is reflected in the balance sheet and the bank loses a certain part of its assets. Since the sum of assets must equal the sum of liabilities, the bank writes off an equal value of liabilities (firstly owners' equity gets eradicated ${ }^{3}$, then claims of other creditors). Let us suppose that the bank suffered a shock of size and hence it holds that

$$
l_{i}-a i=\Delta_{i}
$$

The external behaviour of the bank then depends on the size of the shock:

a) In the first place, the shock hits the bank's net worth. If $n_{-} w_{i}>\Delta_{i}$, which means that the bank is able to cover the losses from its own funds, then the whole shock is absorbed by the bank's capital and it is not propagated further.

3 As mentioned earlier, we simulate only a short period of banking system stress. Thus the net worth behaves only as a shock absorber and cannot be replenished during the simulation, e.g. by accumulating retained earnings. 
b) If $n \_w_{i}<\Delta_{i}$, the residual shock further spreads to the interbank liabilities $b_{i}$, which means that it is uniformly transferred onto the creditor banks up to the value of the interbank liabilities. Hence, if there are creditor banks, in the next round each creditor bank receives a shock of

$$
\min \left(\frac{\Delta i-n_{-} w_{i}}{m}, \frac{b_{i}}{m}\right)
$$

As the propagating bank is not able to honour its debt, it defaults and it is removed from the system. The creditor banks evaluate the received shock in the next lap of the simulation. The simulation ends with a lap when no bank propagates the shock further. Additionally, it holds that:

i. If $b_{i}>\Delta_{i}-n_{-} w_{i}$, there is no residual shock to be transferred to the depositors.

ii. If $b_{i}<\Delta_{i}-n \_w_{i}$, the shock remainder is compensated by the external liabilities which means that the residual loss is covered by the depositors.

\subsubsection{Effects of capital regulation}

Capital regulation is modelled by a rule which measures whether a bank meets a strict capital adequacy ratio and in case of non-compliance it deprives the bank of its license. If $\frac{n_{-} w_{i}}{a_{i}}<C A D 1$, where $C A D 1$ is the strict capital adequacy requirement, the bank is removed from the system similarly as if it defaulted:

a) In order to repay its debt, the bank sells all its assets. Subsequently, it settles its debts from the funds it obtains by the asset sale. First, this pool of funds is used for the repayment of external liabilities. Second, the creditor banks are compensated by the repayment of interbank liabilities. If the bank is not able to repay its interbank liabilities, it uniformly transfers the loss onto the creditor banks. Finally, in the case that there are any funds left after settling all the bank's debt, they disappear from the system.

b) To be able to finally remove the bank from the system, we also have to ensure that it does not have any claims against other banks. As mentioned above, we assume that the bank in liquidation sells all its assets. Since the claims on the debtor banks are sold to some external entity, these banks move the equivalent amount from their interbank liabilities to their external liabilities.

As the capital ratio varies in all simulations, the $C A D 1$ ratio cannot be set directly. Instead, we need to express the $C A D 1$ ratio as a percentage of the initial capital ratio by using the following parameter:

$$
\text { removal_ratio }=\frac{C A D 1}{\gamma}
$$

In our simulations, this parameter reaches values from 0 to 1 , and can be interpreted as the relative gap between the initial capital endowment to the critical CAD1 level. If the removal_ratio equals zero, no banks are removed as the regulation is switched off. If, on the other hand, the removal_ratio equals unity, it means that the capital the 
banks are initialized with equals the $C A D 1$ requirement and thus a bank is removed immediately when its capital ratio falls below the initial level. Given a particular value of $\gamma$ and removal_ratio, we can always calculate the exact $C A D 1$ requirement.

\subsection{Model control}

For each comparative statics experiment, the model is run under several parameter settings which vary in predefined ranges. These intervals from which we draw the parameter combinations then form the axes of the charts. To obtain the observed values, for each parameter combination we run the model in several iterations, each with a different realization of the random network, and we average the result into a single data point.

\section{Simulation Results}

\subsection{Basic behaviour under several types of shocks}

First, we run the model in the basic setting. All the parameters are left at values stated in Table 1 apart from $n_{w_{i}}$ and $p$, which are on the axes of the charts, and $\alpha$, which equals zero for the first experiment and unity for the second one. Similarly to Nier et al. (2007) or Gai et al. (2010), we hit a random bank in the system by wiping out all of its external assets. The results of the first experiment are similar to Nier et al. (2007). On the left-hand chart of Figure 1, we see that the model behaviour is non-linear in both parameters. First, we look at the comparative statics under varying capital ratio. When these ratios are sufficiently high, at reasonably high connectivity levels, the only bank which defaults is the one on which we imposed the original shock. When the capital ratio is between $1 \%$ and $4 \%$ (depending on the connectivity), the loss buffers of the first line of the initial banks' creditors are large enough to absorb the losses, which is the reason the number of defaults stays almost constant. However, if the capital ratio falls below this range, the first-line creditor banks default as well, spreading the losses in further laps of failures.

Second, as the probability of connecting two nodes varies while the total amount of interbank assets remains the same, since equation (1) holds, higher probabilities of connection lead to lower interbank exposures and hence lower riskiness that the initial shock triggers further rounds of defaults. Moreover, as we see in the left-hand chart of Figure 1, except for the situations with very low connectivity, the interbank system has high potential of absorbing the initial shock. For higher probabilities of connection, the relationship of the depositor losses and capital ratio is almost linear. On the other hand, higher connectivity means that more banks are exposed to the initial shock-propagator, and hence especially for capital ratios close to zero, it results in more defaults as we can see in the left-hand chart of Figure 1. 
Figure 1

Number of Defaults (local shock, basic parameter setting)
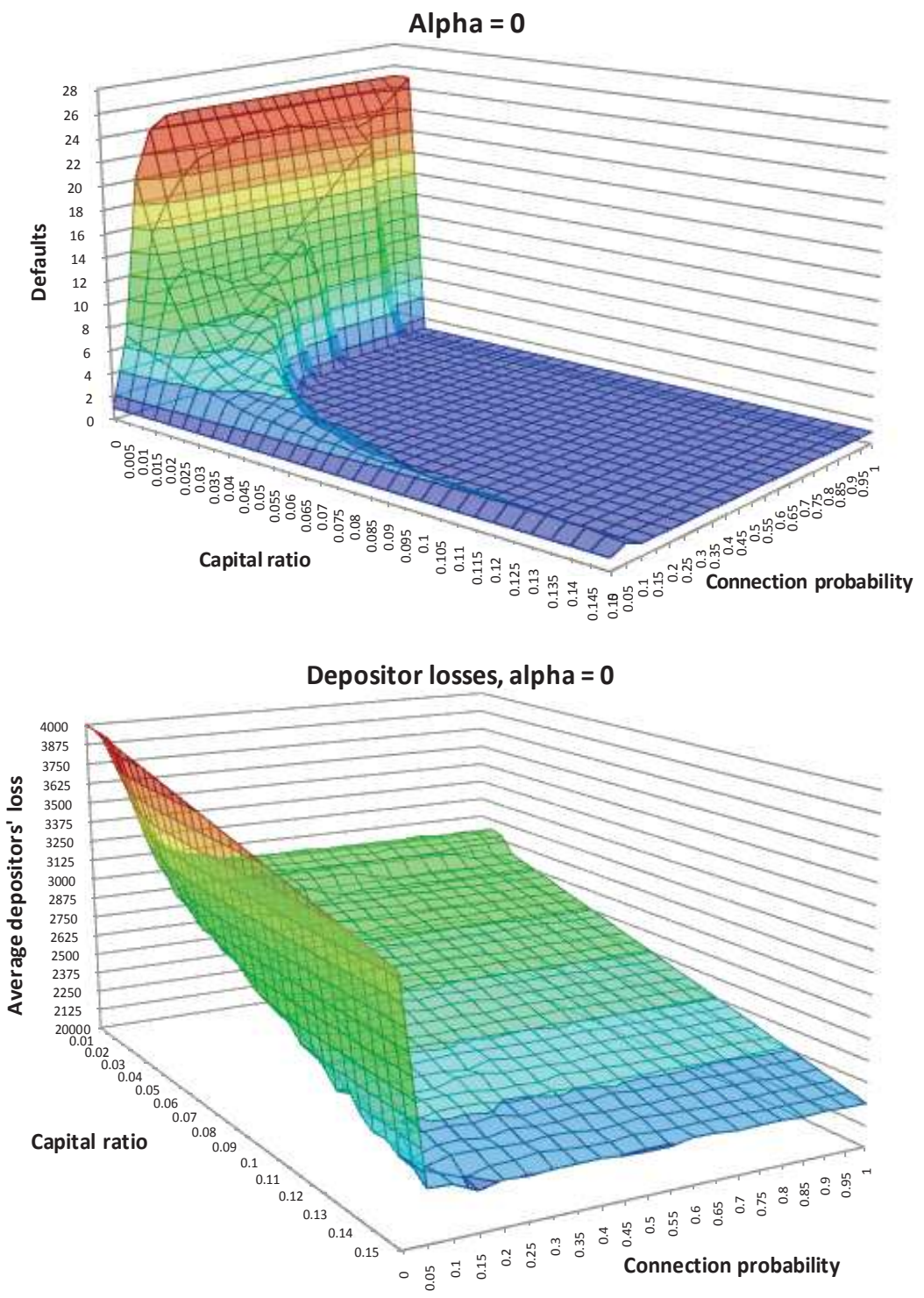

Source: Authors.

Generally, the smaller the capital buffer, the larger connectivity is needed to prevent a systemic crisis. Again, the left-hand chart of Figure 1 shows a "safe zone" of sufficient capital level and reasonably high connectivity, where the only bank to default is the one that is originally shocked. This area presents desirable parameter settings and in reality, both these two parameters are subject to regulation: the capital measures are 
the main building block of the Basel agreements and the regulation of connectivity is performed by the large exposure limits which ensure that a bank's interbank assets are diversified to reduce the credit concentration risk. ${ }^{4}$ Clearly, though, when the capital ratio is too small, the risk cannot be absorbed even with very high connectivity levels. Figure 1 also confirms the results by Mistrulli (2011), who concluded that the ex ante maximum entropy assumption (which in our model equals the assumption that $p=1$ ) underestimates the risk of systemic crisis.

Also, a situation may occur when all banks suffer minor losses, which happens when certain percentage of loans has to be written-off or when an asset which all of the banks possess drops in price. Figure 2 displays a short interval of $7.5 \%$ to $10 \%$ on which increasing connectivity results in shock dispersion and increased system resilience. With even lower capital ratios, there is a threshold level behind which all banks in the system default. The sudden occurrence of systemic break-down is caused by the relative homogeneousness of the banks' balance sheets. Since the only mechanism by which the banks differ from each other is the random network initialization and since the interbank assets account for relatively small portion of the total assets, the banks' capital buffers are of similar size.

Figure 2

Number of Defaults (global shock)

Global shock $=0.1$

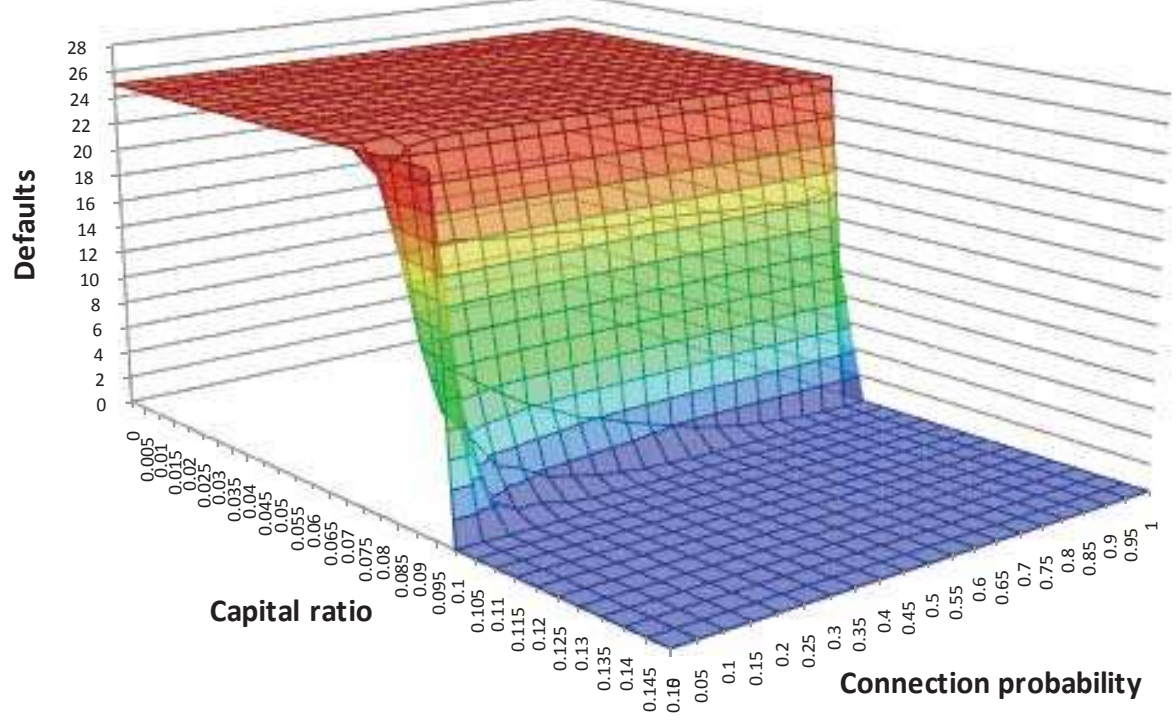

Source: Authors

4 Credit concentration risk is addressed by the EU Directive No. 2006/48/EC. 


\subsection{CAD1 measure}

As to the capital regulation, up until now we have focused only on the capital ratio describing the actual size of the banks' capital buffers. However, it is not possible to simply prescribe a capital ratio and count on all banks' compliance. There must be repressive mechanisms ensuring that all the banks keep their capital levels high enough, such as a ban on operation. Thus, we observe what happens if the banks that do not comply with the regulation are deprived of their license. The results are presented as follows: the top left-hand chart depicts the average number of banks that ended operation, either because they defaulted or because they were removed for not meeting the regulatory requirements, the top right-hand chart presents the number of banks removed by the regulator and the bottom left one the banks that defaulted and imposed losses on the rest of the system. The top right and the bottom left-hand charts result in the top left one when summed up. Finally, the bottom right-hand chart depicts the losses suffered by the depositors. On one axis there is the capital ratio, on the other one there is the removal ratio as defined by equation (2).

First, we examine a local shock hitting one random bank, a situation depicted in Figure 3. For high capital levels, the regulation takes out the banks that would not otherwise default, but when the capital buffers are small, the banks default before the regulation manages to remove them from the system. Hence, this measure fails to improve the system resilience and moreover, we see that the same holds for the depositor protection.

Figure 3

\section{CAD1 Measure (local shock)}

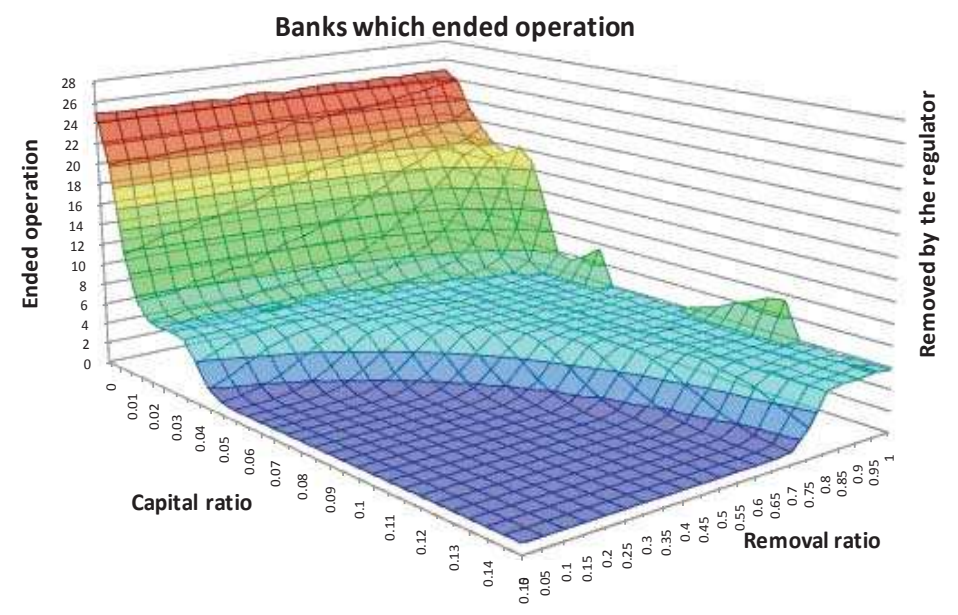




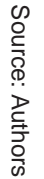

Average depositors' loss

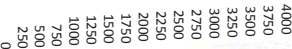

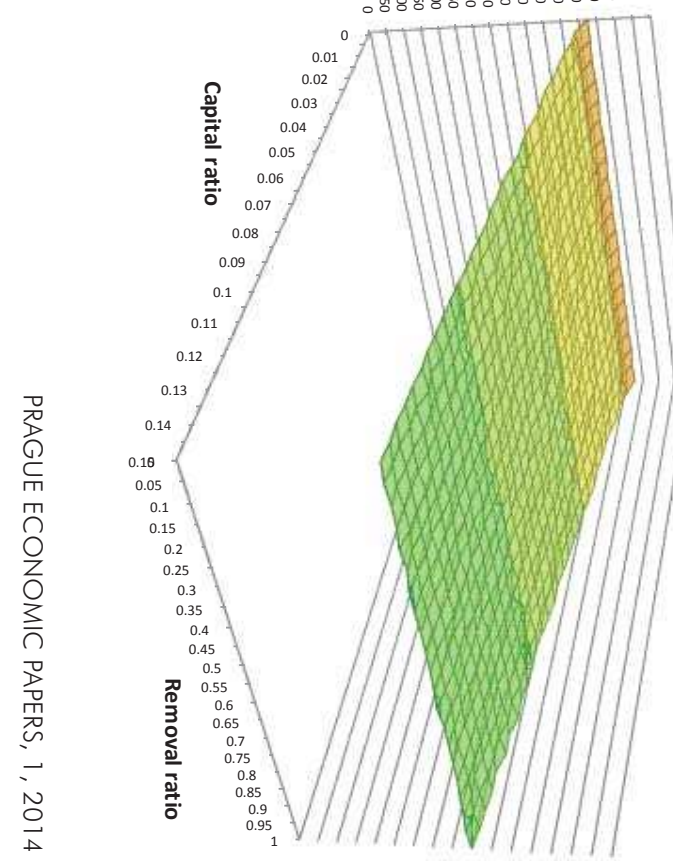

Defaults

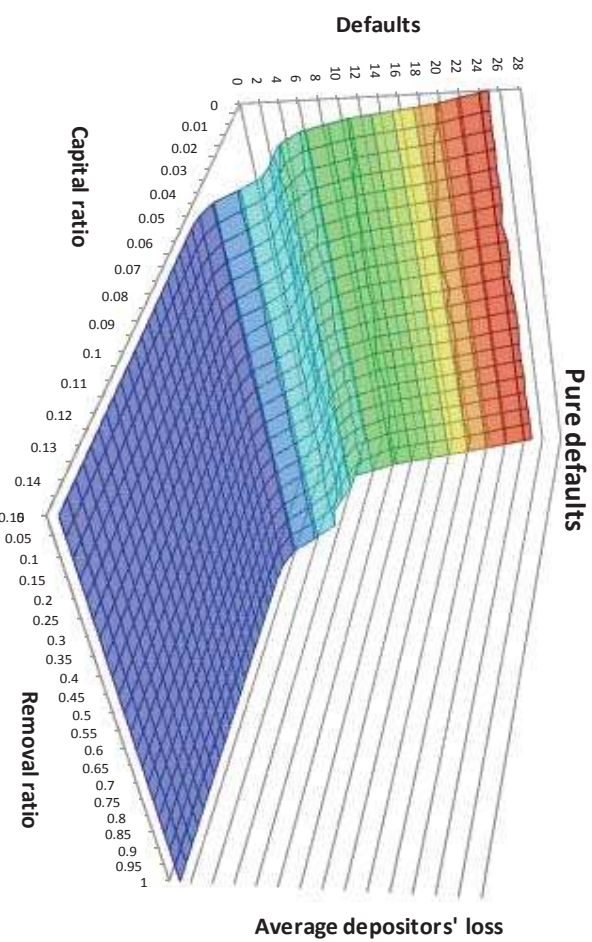

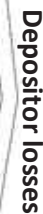

w

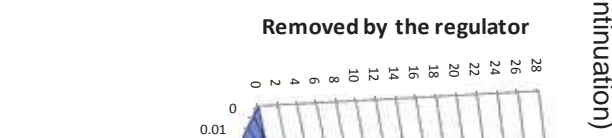

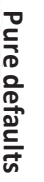

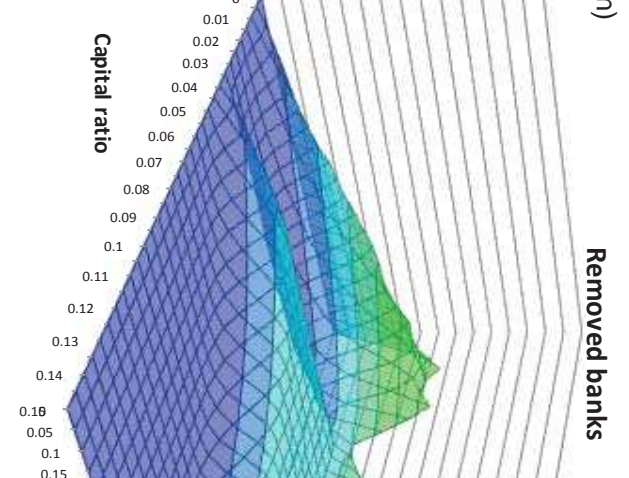

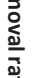

$\stackrel{2}{\frac{2}{0}}$

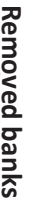

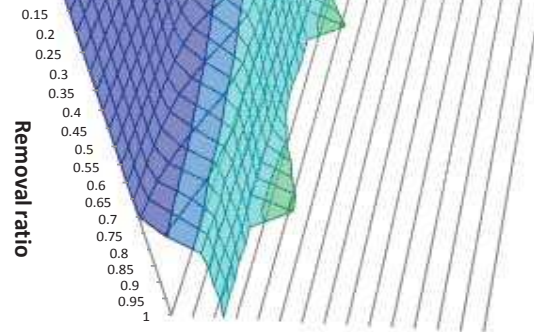


Next, we study the case of a shock affecting all banks. Figure 4 implies that for small capital buffers (until approximately 2.5\%), no banks are removed since almost all of them default right after accepting the shock. However, this situation differs from the one of a local shock in two aspects. First, as we can see in the top right-hand chart of Figure 4, high removal ratios cause the regulator to remove all banks in the system even though their capital buffers would be large enough for them to withstand the shock, which is clearly a rather unrealistic result. ${ }^{5}$ Second, there is an interval of capital ratios (approximately $[2.5 \%, 5 \%]$ ), where the regulation succeeds in lowering the number of defaulted banks and the depositor losses. However, this result is quite insignificant compared to the number of banks shut down by the regulator.

\section{Figure 4}

\section{CAD1 Measure (global shock)}

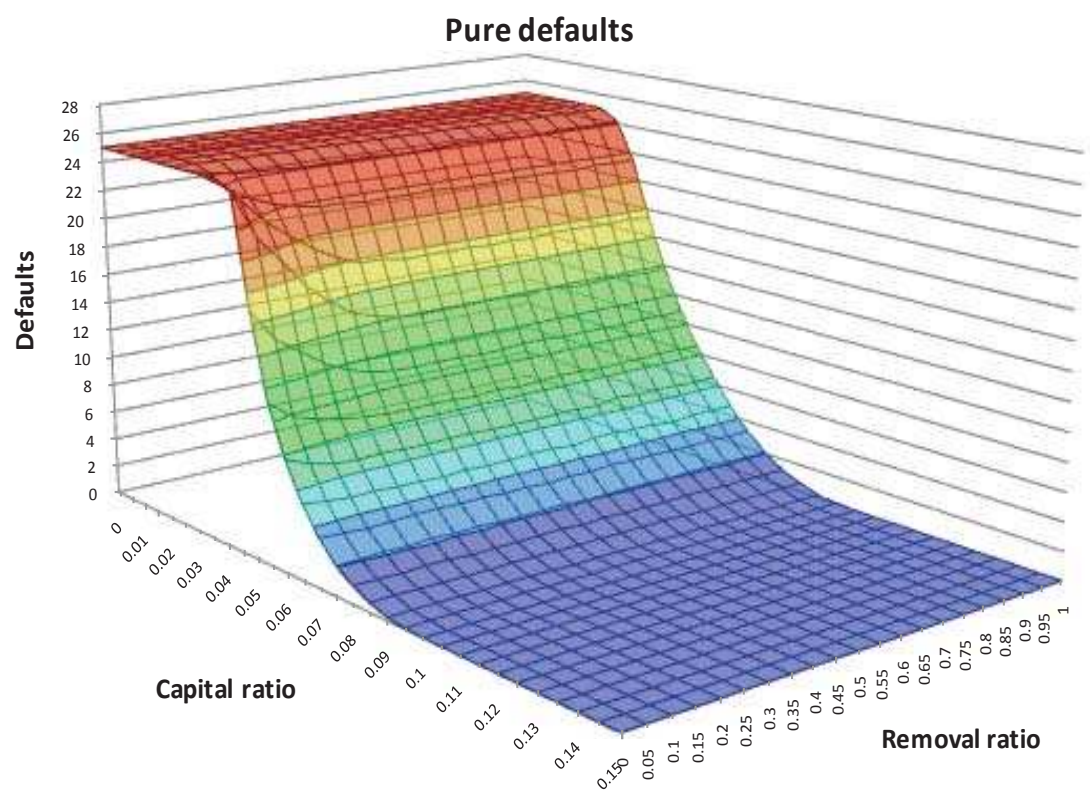

5 In reality, the removal threshold does not account for $100 \%$ of the capital the banks ought to have (for example, according to The Act on Banks 21/1992 Coll., the Czech banks should end their operation when their capital ratios fall below one third of the original Basel requirements). Also, we would expect many of the institutions to be bailed out instead of deprived of their licenses. 
Figure 4 (Continuation) Removed banks
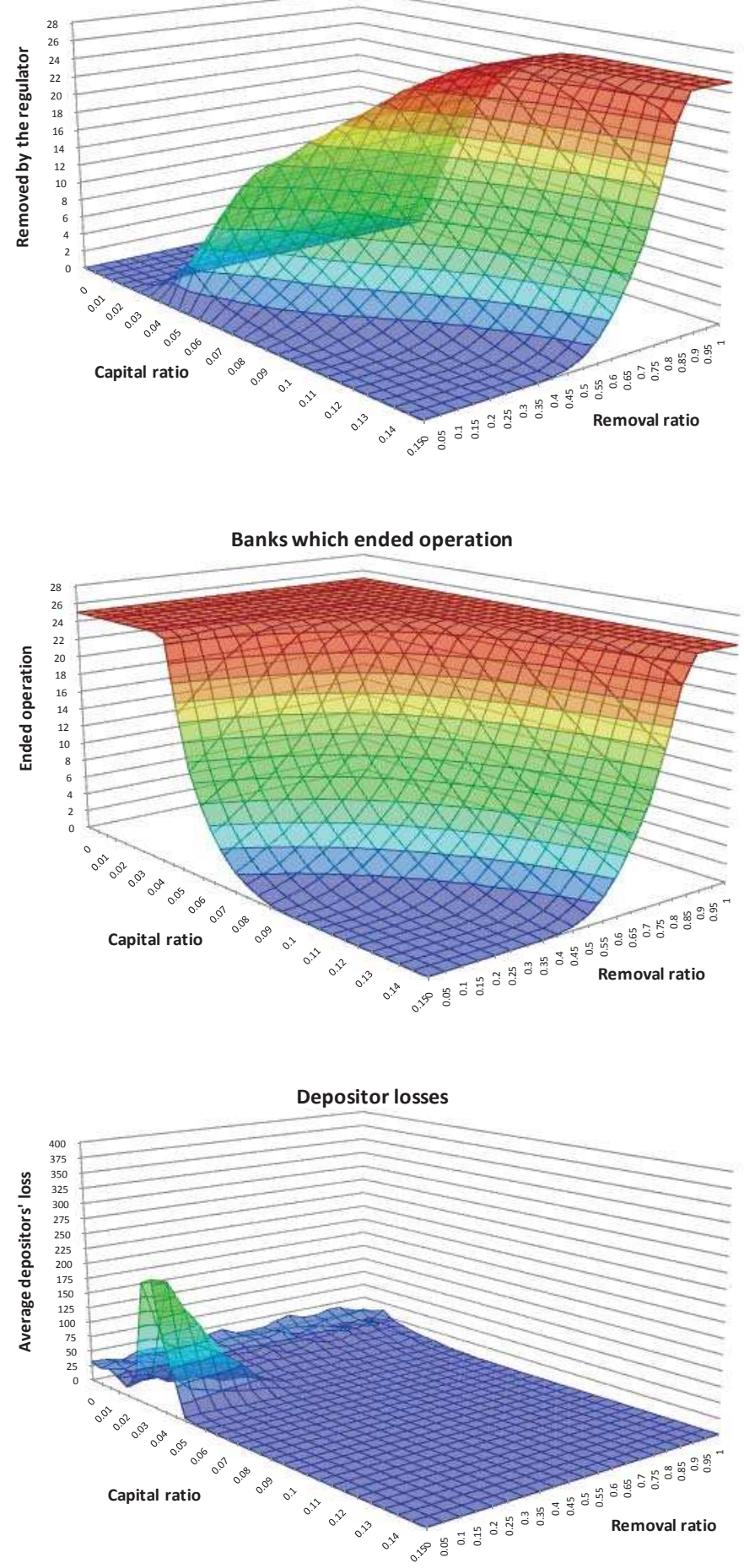

Source: Authors 
Finally, we should repeat that the removal of the troubled banks from the system might be inefficient when a crisis emerges, but it is very important as a coercive measure to ensure that the capital buffers of the banks are large enough. Clearly, without the threat of a ban on operation, the banks would be much less willing to limit their leverage. When we think about the $C A D 1$ measure as a necessity for ensuring certain capital buffers, i.e. when we fix the removal ratio and consider the inverted relationship $\gamma=$ removal_ratio $_{f x} \cdot C A D 1$, we see that there are obvious effects on the system's resilience.

\section{Summary of Simulation Results and Further Research Opportunities}

Table 3 presents a summary of the simulation results. First, it is obvious that the levels of individual banks' capital buffers are crucial for systemic stability. Moreover, the relationship between the capital ratio and the number of defaults in most of the situations appears to be of a "step-like" shape with sudden occurrence of a systemic breakdown rather than of a gradual nature. Hence, the regulatory protection needs to be scaled for much larger shocks which may not be very likely to occur but when they do, once the stress situation breaks through the capital barriers and triggers a system-wide crisis, the impact is devastating.

Second, once a crisis breaks out, the ad-hoc discretionary measures alone, forcing the troubled banks to end operation (or sell a part of their assets, even though this possibility is left for further research), have almost no or very little effect on improving the situation. Moreover, when the illiquidity is high, any measure which increases the number of removed banks and assets sold in the market would only aggravate the breakdown and be rather counter-productive. However, since CAD1 contributes to maintaining the overall capital ratios, it is worth the extra costs it generates. The best option would seem to be to use it as preventive measure that forces the banks to have enough capital but do not use it in major distress. On the contrary, during the crisis, measures that prevent the banks from propagating the shocks through the network are more appropriate - such as state bail-outs. This forms a typical dynamic inconsistency problem and may result in increased moral hazard.

Several further research opportunities exist since the basic modelling framework presented in this paper is very flexible and easily used for simulations of financial systems behaviour in different institutional and regulatory environments. Firstly, it is interesting to explore other parameter combinations as well. For example, the number of banks and particularly the interbank assets ratio are parameters that also have effect on the stability of the banking system. Nier, et al. (2007) describe how the system behaves under different interbank assets ratios and finds that increasing this parameter up to a certain level leads to enhanced shock propagation. Moreover, it would be interesting to endogenize this ratio and study how the system would be affected if the banks were reluctant to renew their loans to counterparties whose capital ratio fell below a certain level. 
Table 3

\section{Results Summary}

\begin{tabular}{|c|c|c|}
\hline Experiment & & \\
\hline \multirow[t]{2}{*}{$\begin{array}{l}\text { Basic } \\
\text { behaviour }\end{array}$} & Local & $\begin{array}{l}\text { - Large capital buffers are the essential means to ensure systemic } \\
\text { stability. } \\
\text { - Given a fixed value of interbank assets, the more is the system } \\
\text { intertwined, the more resilient it is against total breakdown. } \\
\text { - On the other hand, higher number of interbank connections makes } \\
\text { the system more fragile when the capital levels are low. } \\
\text { - There are "safe zones" where sufficiently high capital buffers and } \\
\text { enough connectivity ensure that the shock is absorbed in the system. }\end{array}$ \\
\hline & Global & $\begin{array}{l}\text { - On a small range of capital ratios when the crisis is phasing in, } \\
\text { the interbank connections have shock dispersion effects and reduce } \\
\text { the number of defaults. } \\
\text { - The more heterogeneous are the banks' balance sheets, the larger } \\
\text { interval of capital ratios it takes for the system to break down. }\end{array}$ \\
\hline \multirow[t]{3}{*}{$\begin{array}{l}\text { CAD1 } \\
\text { measure } \\
\text { (bank } \\
\text { removal) }\end{array}$} & Local & $\begin{array}{l}\text { - For high capital levels, the regulation takes out the banks that would } \\
\text { not otherwise default. } \\
\text { - When the capital buffers are small, the banks default before } \\
\text { the regulation manages to remove them from the system. } \\
\text { - This measure fails to reduce the number of failed banks as well as } \\
\text { the amount of depositor losses. }\end{array}$ \\
\hline & Global & $\begin{array}{l}\text { - High removal ratios cause that the all banks are removed even though } \\
\text { their capital buffers would be large enough for them to withstand } \\
\text { the shock. } \\
\text { - There is a very small interval of capital ratios where the regulation } \\
\text { succeeds to lower the number of defaulted banks and the depositor } \\
\text { losses. }\end{array}$ \\
\hline & $\begin{array}{l}\text { Local, } \\
\text { global }\end{array}$ & $\begin{array}{l}\text { - When we think about the CAD1 measure as a necessity for ensuring } \\
\text { certain capital buffers, we see that it has obvious positive effects on the } \\
\text { system's resilience. }\end{array}$ \\
\hline
\end{tabular}

Source: Authors

Second, our model can be easily extended to capture regulatory measures incorporated in Basel III such as liquidity regulation or capital conservation buffer. Also, we are working on the implementation of a systemic surcharge for the too-interconnected-to-fail banks. Unfortunately, due to the scope of this paper, not all the aspects of the model could have been described. In addition, our model assumes a random interbank network, which is an assumption that can be replaced by more sophisticated network structures that are closer to reality, e.g. the small-world networks or scale-free tiered structures. The occurrence of the systemic breakdown would be also probably less sudden and more gradual if the modelled banks were more heterogeneous - in this case it is possible that given a certain shock size, regulatory measures would prove efficient on a wider range of overall capital ratio. Ideally, the effects of regulation may be studied on the real-world interbank network data. Moreover, because of its agent-based nature, it is possible to extend the model with other features, such as endogenous network creation or more types of agents, such as central banks, hedge funds or individual depositors. 


\section{Conclusion}

As a result of the recent global economic crisis, a revision of the current regulatory framework was necessary. In theory, Basel III should increase the system's resilience by redefining current capital requirements and adding new measures. In practice, however, we believe that Basel III will fail as both Basel I and II did. In order to better understand the effects of regulation on systemic risk, we have constructed an agent-based network model of a banking system and used it for stress-testing of several different settings of regulatory environment. First, our simulations confirm that sufficient capital buffers of individual banks are crucial for protecting the stability of the whole system. Second, we see that the regulatory measures work best as a preventive measure which ensures that the banks possess sufficient capital buffers. However, they are not very effective once the system is collapsing, and if the overall market liquidity is low, they can even worsen the situation. Finally, there are issues with data availability. Since even the regulators do not usually precisely know how the real-world interbank exposures look like and because the maximum entropy approach used for estimation of these data underestimates the systemic risk, it is necessary that the banks provide more detailed data on their exposures so that the banking system models may be more efficient in exposing potential weaknesses. Were the interbank relationships more transparent, it would be much easier to pinpoint the potential weaknesses and devise targeted regulatory measures for systemic stability protection.

\section{References}

Allen, F., Babus, A. (2009), "Networks in Finance," in Kleindorfer, P. R. et al., The Network Challenge. Wharton School Publishing, pp. 367-382.

Allen, F., Gale, D. (2000), "Financial Contagion.“ Journal of Political Economy. Vol. 108, No. 1, pp. 1-33.

Battiston, S., Gatti, D. D., Gallegati, M., Greenwald, B., Stiglitz, J. (2012), "Default Cascades: When Does Risk Diversification Increase Stability?" Journal of Financial Stability, Vol. 8, No. 3, pp. 138-149.

BCBS. (2011), Basel III: A Global Regulatory Framework for More Resilient Banks and Banking Systems. Bank for International Settlements.

Boss, M. et al. (2004), "The Network Topology of the Interbank Market." Quantitative Finance. Vol. 4, No. 6, pp. 677-684.

Brunnermeier, M. et al. (2009), The Fundamental Principles of Financial Regulation: Geneva Reports on the World Economy, Centre for Economic Policy Research.

Cifuentes, R., Ferruci, G., Shin, H. S. (2005), "Liquidity Risk and Contagion." Journal of the European Economic Association. Vol. 3, No. 2-3, pp. 556-566.

ECB. (2010), Recent Advances in Modelling Systemic Risk Using Network Analysis. European Central Bank.

Erdös, P., Rényi, A. (1959), "On Random Graphs.“ Publicationes Mathematicae. 1959, Vol. 6, pp. 290-297. 
Frait, J., Komárková Z. (2011), "Financial Stability, Systemic Risk and Macroprudential Policy." Czech National Bank Financial Stability Report 2010/2011, pp. 96-111.

Freixas, X., Parigi, B., Rochet, J. C. (2000), "Systemic Risk, Interbank Relations and Liquidity Provision by the Central Bank." Journal of Money, Credit, and Banking. Vol. 32, No. 3, pp. 611-638.

Gai, P., Kapadia, S. (2010), "Contagion in Financial Networks." Proceedings of the Royal Society A. 2010, Vol. 466, No. 2120, pp. 2401-2423.

Geršl, A., Jakubík, P. (2010), "Procyclicality of the Financial System," in Czech National Bank, Financial Stability Report 2009/2010, pp. 110-119.

Geršl, A., Jakubík, P. (2012), "How Important Is the Adverse Feedback Loop for the Banking Sector?" Journal of Economics, Vol. 60, No. 1, pp. 32-49.

IMF. (2009), Global Financial Stability Report: Responding to the Financial Crisis and Measuring Systemic Risks, International Monetary Fund, April 2009.

Klinger, T. (2011), "Banking Regulation: Assessment and Simulation of Regulatory Measures." Bachelor Thesis. Prague: Institute of Economic Studies, Faculty of Social Sciences, Charles University.

Lall, R. (2010), "Reforming Global Banking Rules: Back to the Future?" DIIS Working Paper No. 16.

Matejašák, M., Černohorský, J., Teplý, P. (2009), “The Impact of Regulation of Banks in the US and the EU-15 Countries", E a M: Ekonomie a Management, Vol. 3, pp. 58-69.

Mistrulli, P. E. (2011), "Assessing Financial Contagion in the Interbank Market: Maximum Entropy versus Observed Interbank Lending Patterns." Journal of Banking \& Finance, Vol. 35, No. 5, pp. 1114-1127.

Muller, J. (2006), "Interbank Credit Lines as a Channel of Contagion." Journal of Financial Services Research. Vol. 29, No. 1, pp. 37-60.

Nier, E. et al. (2007), "Network Models and Financial Stability." Journal of Economic Dynamics and Control. Vol. 31, No. 6, pp. 2033-2060.

Rippel, M., Teplý, P. (2011), "Operational Risk - Scenario Analysis.“ Prague Economic Papers, 2011, Vol. 20, No. 1, pp. 23-39.

Sheng, A. (2010), "Financial Crisis and Global Governance: A Network Analysis." In Commission on Growth and Development, Globalization and Growth: Implications for a Post-Crisis World, pp. 69-93.

Shin, H. S. (2008), "Risk and Liquidity in a System Context." Journal of Financial Intermediation. Vol. 17, No. 3, pp. 315-329.

Šútorová, B., Teplý, P. (2013), "The impact of Basel III on lending rates of EU banks," Czech Journal of Finance, Vol. 63, No. 3, pp. 226-243.

Teplý, P., Diviš, K., Černohorská, P. (2007), "Implications of the New Basel Capital Accord for European Banks." E+M Journal, Vol. 1/2007, pp. 59-65.

Teplý, P., Vrábel, M., Černohorská, L. (2012), "The VT Index as an indicator of market liquidity risk in Slovakia." Ekonomický časopis. Vol. 60, No. 3, pp. 223-238.

Upper, C., Worms, A. (2004), "Estimating Bilateral Exposures in the German Interbank Market: Is There a Danger of Contagion?" European Economic Review. Vol. 48, No. 4, pp. 827-849.

Upper, Ch. (2011), "Simulation Methods to Assess the Danger of Contagion in Interbank Markets." Journal of Financial Stability. Vol. 7, No. 3, pp. 111-125.

Van Lelyveld, I., Liedorp, F. (2006), "Interbank Contagion in the Dutch Banking Sector: A Sensitivity Analysis." International Journal of Central Banking. Vol. 2, pp. 99-133.

Wells, S. (2004), "Financial Interlinkages in the United Kingdom's Interbank Market and the Risk of Contagion." Bank of England Working Paper No. 260. 